\title{
HLA-A1101 Positive Cells Present
}

National Cancer Institute

\section{Source}

National Cancer Institute. HLA-A1101 Positive Cells Present. NCI Thesaurus. Code C140184.

A laboratory test result indicating the presence of HLA-A1101 positive cells in a tissue sample. 